\title{
HUBUNGAN KEPATUHAN MINUM OBAT TERHADAP TINGKAT KEKAMBUHAN PASIEN SKIZOFRENIA DI POLI JIWA RSUD. DR. H. MOCH. ANSARI SALEH BANJARMASIN
}

\section{The Relationship Between Medication Adherence To The Recurrence Rate Of Schizophrenic Patients In Psychiatric Outpatient RSUD dr. H Moch. Ansari Saleh Banjarmasin}

\author{
Muliyani ${ }^{1}$, Nazhipah Isnani ${ }^{1}$, Ravenalla Abdurrahman Al Hakim Sampurna Putra Solihin ${ }^{2}$ \\ Program Studi D-III Farmasi \\ Politeknik Unggulan Kalimantan ${ }^{1}$ \\ Program Studi D-III Perekam Medis Dan Informasi Kesehatan \\ Politeknik Unggulan Kalimantan² \\ Email: muliyani@polanka.ac.id
}

\begin{abstract}
ABSTRACK
Treatment of schizophrenia is one of the main factors for the patient's success to recover. Patients not adhere to treatment will have a higher risk of recurrence than patients who adhere to treatment. This research aims to determine the relationship of medication adherence to the recurrence rate of schizophrenic patients in the Psychiatric Psychology Hospital dr. H. Moch. Ansari Saleh Banjarmasin. Type of research is quantitative with prospective and retrospective observational data collection. The sample population was all schizophrenic patients who underwent outpatient treatment for 12 month at the Psychiatric Outpatient Polyclinic RSUD dr. $H$. Moch. Ansari Saleh Banjarmasin meet the inclusion criteria. The number of research subjects was 50 patients. The result of the research based on the Chi-square test that $\rho$-value $=0,01$ is smaller than $\alpha=0,05$ which indicates that $H_{0}$ is rejected, so there is a relationship between adherence to taking medication and the recurrence of schizophrenia patients in the Psychiatric Outpatient Polyclinic RSUD dr. H. Moch. Ansari Saleh Banjarmasin.
\end{abstract}

Keywords: Schizophrenia, patient criteria, outpatient

\begin{abstract}
ABSTRAK
Penatalaksanaan pengobatan skizofrenia merupakan salah satu faktor utama keberhasilan penderita untuk sembuh. Pasien yang tidak patuh pada pengobatan akan memiliki resiko kekambuhan lebih tinggi dibandingkan dengan pasien yang patuh pada pengobatan. Penelitian ini bertujuan untuk mengetahui hubungan kepatuhan minum obat terhadap tingkat kekambuhan pasien skizofrenia di Poli Jiwa RSUD dr. H. Moch. Ansari Saleh Banjarmasin. Jenis penelitian adalah kuantitatif dengan pengambilan data secara observasional prospektif dan retrospektif. Populasi sampel adalah semua pasien skizofrenia yang menjalani pengobatan rawat jalan selama 12 bulan di Poli Jiwa Rawat Jalan RSUD dr. H. Moch. Ansari Saleh Banjarmasin yang memenuhi kriteria inklusi. Jumlah subyek penelitian sebanyak 50 pasien. Hasil penelitian berdasarkan uju statistik Chi-square menunjukkan bahwa $\rho$-value $=0,01$ lebih kecil dari nilai $\alpha=$ 0,05 yang menunjukkan bahwa $\mathrm{H}_{0}$ ditolak, maka terdapat hubungan antara kepatuhan minum obat dengan tingkat kekambuhan pasien skizofrenia di Poli Jiwa Rawat Jalan RSUD dr. $H$. Moch. Ansari Saleh.
\end{abstract}

Kata kunci : Skizofrenia, kriteria pasien, rawat jalan 


\section{PENDAHULUAN}

World Health Organization (WHO), terdapat sekitar 35 juta orang terkena depresi, 60 juta orang terkena bipolar, 21 juta terkena skizofrenia, serta 47,5 juta terkena demensia (WHO, 2016). Di Indonesia dengan berbagai faktor biologis, psikologis dan sosial dengan keanekaragaman penduduk; maka jumlah kasus gangguan jiwa terus bertambah yang berdampak pada penambahan beban negara dan penurunan produktivitas manusia untuk jangka panjang (Depkes RI, 2016). Di Indonesia berdasarkan hasil Riset Kesehatan Dasar (Riskesdas), menunjukkan bahwa prevalensi gangguan mental emosional yang ditunjukkan dengan gejala-gejala depresi dan kecemasan adalah sebesar 6\% untuk usia 15 tahun ke atas atau sekitar 14 juta orang. Sedangkan, prevalensi gangguan jiwa berat, seperti skizofrenia adalah 1,7 per 1000 penduduk sekitar 400.000 orang (Depkes RI, 2013).

Skizofrenia adalah suatu penyakit yang mempengaruhi otak dan menyebabkan timbulnya pikiran, persepsi, emosi, gerakan dan perilaku yang aneh dan terganggu. Menurut DSM-IV-TR (Diagnostik and Statistical Manual of Mental Disorders), skizofrenia terdiagnosis pada masa remaja akhir dan dewasa awal. Awal terjadinya skizofrenia pada usia 15-25 tahun untuk pria dan 25-35 tahun untuk wanita (Videback, 2008). Pasien dengan diagnosis skizofrenia diperkirakan akan kambuh $50 \%$ pada tahun pertama, $70 \%$ pada tahun kedua dan $100 \%$ pada tahun kelima setelah pulang dari rumah sakit. Faktor-faktor yang mempengaruhi kekambuhan pasien skizofrenia yaitu pasien, penanggung jawab pasien (care manager), dokter, dan keluarga pasien (Kelliat, 2011). Salah satu faktor untuk mencegah terjadinya kekambuhan pada pasien skizofrenia yaitu dengan melaksanakan program pengobatan dengan rutin, pengobatan yang dimaksud dalam penelitian ini adalah kepatuhan pasien dalam minum obat.

Perilaku patuh minum obat berpengaruh pada remisi waktu pasien satu tahun lebih lama dan gejala psikosis tidak akan terlalu parah. Penatalaksanaan pengobatan skizofrenia merupakan salah satu faktor utama keberhasilan penderita untuk sembuh. Pasien yang tidak patuh pada pengobatan akan memiliki resiko kekambuhan lebih tinggi dibandingkan dengan pasien yang patuh pada pengobatan (Yuliantika, 2012).

Terapi yang komprehensif dan holistik, dewasa ini sudah mulai dikembangkan meliputi terapi obat-obatan anti skizofrenia (psikofarmaka), psikoterapi, terapi psikososial dan terapi psikoreligius. Terapi psikofarmaka harus diberikan dalam jangka waktu yang lama. Hal ini dimaksudkan untuk menekan sekecil mungkin kekambuhan (relaps). Keberhasilan terapi gangguan jiwa tidak hanya terletak pada terapi obat psikofarmaka dan jenis terapi lainnya, tetapi juga peran serta keluarga dan masyarakat turut menentukan (Hawari, 2011).

Berdasarkan latar belakang tersebut, maka peneliti perlu tertarik untuk melakukan penelitian terkait permasalahan tersebut untuk mengetahui apakah ada hubungan antara kepatuhan minum obat terhadap tingkat kekambuhan pada pasien skizofrenia di Poli Jiwa Rawat Jalan RSUD dr. H. Moch. Ansari Saleh Banjarmasin.

\section{METODE PENELITIAN}

Penelitian ini menggunakan metode kuantitatif dengan mengambil data secara observasional prospektif dan retrospektif. Teknik pengambilan sampel menggunakan teknik purposive sampling. Kriteria inklusi pada penelitian ini yaitu pasien dengan diagnose skizofrenia (ICD 10 F20). Jenis data yang digunakan adalah data primer dan sekunder. Data primer diperoleh dengan cara wawancara dan pengisian kuisioner terstuktur oleh pasien, sedangkan data sekunder diambil dari catatan medis pasien. 


\section{HASIL DAN PEMBAHASAN}

Pengambilan sampel pada penelitian ini sebanyak 50 pasien skizofrenia yang telah memenuhi kriteria inklusi penelitian yang diambil dari Poli Jiwa Rawat Jalan dan ruangan Rekam Medis RSUD dr. H. Moch. Ansari Saleh Banjarmasin.

\section{a. Distribusi Tingkat Kepatuhan Minum Obat Pasien Skizofrenia}

Tingkat kepatuhan minum obat pasien skizofrenia berdasarkan hasil penelitian lebih jelasnya dapat dilihat pada tabel 2 sebagai berikut :

Tabel 1. Distribusi tingkat kepatuhan minum obat pasien skizofrenia

\begin{tabular}{lcc}
\hline $\begin{array}{l}\text { Kepatuhan } \\
\text { minum obat }\end{array}$ & $\mathbf{N}=\mathbf{5 0}$ & Persentase (\%) \\
\hline Rendah & 11 & $22 \%$ \\
Sedang & 29 & $58 \%$ \\
Tinggi $\quad$ Total & 10 & $20 \%$ \\
& $\mathbf{5 0}$ & $\mathbf{1 0 0 \%}$ \\
\hline
\end{tabular}

Berdasarkan hasil penelitian pada tabel 2. distribusi tingkat kepatuhan pasien skizofrenia di Poli Jiwa Rawat Jalan RSUD dr. H. Moch. Ansari Saleh Banjarmasin menunjukkan bahwa tingkat kepatuhan minum obat pada pasien skizofrenia tertinggi pada tingkat kepatuhan sedang dengan jumlah 29 orang (58\%). Kepatuhan rendah dengan jumlah 11 orang (22\%) dan kepatuhan tinggi dengan jumlah 10 orang (20\%).

Sesuai dengan penelitian yang dilakukan oleh Naafi (2016) yang menunjukkan bahwa persentase tingkat kepatuhan sedang lebih tinggi sebanyak $90 \%$, tingkat kepatuhan rendah sebanyak $2,5 \%$, dan tingkat kepatuhan tinggi sebanyak $7,5 \%$. Persamaannya terletak pada tingkat kepatuhan sedang yang merupakan tingkat kepatuhan dengan persentase yang tinggi. Dilihat dari data penelitian tingkat kepatuhan minum obat pasien skizofrenia di poli Jiwa Rawat Jalan RSUD dr. H. Moch. Ansari Saleh Banjarmasin menunjukkan bahwa sebagian besar pasien cukup patuh terhadap pengobatan yang dijalankan.

\section{b. Distribusi Tingkat Kekambuhan Pasien Skizofrenia}

Tingkat kekambuhan pasien skizofrenia di Poli Jiwa Rawat Jalan RSUD dr. H. Moch. Ansari Saleh Banjarmasin berdasarkan hasil penelitian lebih jelasnya dapat dilihat pada tabel 3. sebagai berikut :

Tabel 2. Distribusi Tingkat Kekambuhan
Pasien Skizofrenia

Berdasarkan hasil penelitian pada tabel 3. diperoleh tingkat kekambuhan pasien skizofrenia yang tertinggi adalah dengan tingkat kekembuhan sedang berjumlah 25 orang $(50 \%)$, tertinggi kedua adalah dengan tingkat kekambuhan tinggi berjumlah 16 orang (32\%), dan tingkat kekambuhan rendah berjumlah 9 orang (18\%). Berdasarkan teori Andri (2008) kambuh merupakan keadaan pasien dimana muncul gejala yang sama seperti sebelumnya dan mengakibatkan pasien harus dirawat kembali.

Keberlangsungan pengobatan dalam penatalaksanaan skizofrenia merupakan salah satu faktor keberhasilan terapi. Pasien yang tidak patuh dalam pengobatan akan memiliki resiko kekambuhan lebih tinggi dibandingkan dengan pasien yang patuh dalam pengobatan. Ketidakpatuhan berobat merupakan salah satu alasan kembali dirawat dirumah sakit. Pasien yang kambuh membutuhkan waktu yang lebih lama dan dengan kekambuhan yang berulang, kondisi pasien bisa semakin memburuk dan sulit untuk dikembalikan ke keadaan semula. 
Pengobatan skizofrenia ini harus dilakukan terus menerus sehingga pasien nantinya dapat dicegah dari kekambuhan penyakit dan dapat mengembalikan fungsi untuk produktif serta akhirnya dapat meningkatkan kualitas hidup (Yuliantika, 2012)

\section{c. Hubungan tingkat kepatuhan minum obat terhadap tingkat kekambuhan pada pasien} skizofrenia

Hubungan tingkat kepatuhan minum obat terhadap tingkat kekambuhan pada pasien skizofrenia di Poli Jiwa Rawat Jalan RSUD dr. H. Moch. Ansari Saleh Banjarmasin berdasarkan hasil penelitian lebih jelasnya dapat dilihat pada tabel 4.sebagai berikut :

Tabel 3. Hubungan tingkat kepatuhan minum obat terhadap tingkat kekambuhan pada pasien skizofrenia

\begin{tabular}{llllll}
\hline & & & \multicolumn{3}{c}{ Tingkat Kekambuhan } \\
& & & Rendah & Sedang & Tinggi \\
\hline Tingkat & Rendah & $\mathrm{N}$ & 1 & 2 & 8 \\
& & $\%$ & $9.1 \%$ & $18.2 \%$ & $72.7 \%$ \\
\cline { 2 - 6 } & Sedang & $\mathrm{N}$ & 1 & 21 & 7 \\
& & $\%$ & $3.4 \%$ & $72.4 \%$ & $24.1 \%$ \\
\cline { 2 - 6 } & Tinggi & $\mathrm{N}$ & 7 & 2 & 1 \\
& & $\%$ & $70.0 \%$ & $20.0 \%$ & $10.0 \%$ \\
\cline { 2 - 6 } Total & & $\mathbf{N}$ & $\mathbf{9}$ & $\mathbf{2 5}$ & $\mathbf{1 6}$ \\
& & $\%$ & $\mathbf{1 8 . 0} \%$ & $\mathbf{5 0 . 0} \%$ & $\mathbf{3 2 . 0} \%$ \\
\hline
\end{tabular}

Tabel 5. Hasil uji Chi-square

\begin{tabular}{lccr}
\hline & & \multicolumn{2}{c}{$\begin{array}{c}\text { Asymptotic } \\
\text { Significance } \\
\text { (2-sided) }\end{array}$} \\
\hline Pearson Chi-Square & $33.634^{\mathrm{a}}$ & $\mathrm{df}$ & .001 \\
Likelihood Ratio & 29.049 & 4 & .001 \\
Linear-by-Linear & 16.080 & 1 & .001 \\
Association & & & \\
N of Valid Cases & 50 & & \\
\hline
\end{tabular}

Berdasarkan hasil uji statistik Chi-square $\left(x^{2}\right)$ diperoleh hasil $\rho$-value $=0,01$ lebih kecil dari nilai $\alpha=0,05$ yang menunjukkan bahwa $\mathrm{H}_{0}$ ditolak maka terdapat hubungan antara kepatuhan minum obat dengan tingkat kekambuhan pasien skizofrenia di Poli Jiwa RSUD dr. H. Moch. Ansari Saleh. Penelitian ini sesuai dengan penelitian yang dilakukan oleh Kaunang (2015) di Poliklinik Rumah Sakit Prof. Dr. V. L. Ratumbuysang Manado yang menyatakan ada hubungan yang bermakna antara kepatuhan minum obat dengan prevalensi kekambuhan pasien skizofrenia dengan hasil $\rho$-value $=0,000$ yang juga menggunakan uji statistik Chi-square $\left(x^{2}\right)$.

Kepatuhan (compliance) juga dikenal sebagai (adherence) adalah derajat dimana pasien mengikuti anjuran klinis dari dokter yang mengobatinya. Contoh dari kepatuhan adalah mematuhi perjanjian, mematuhi dan menyelesaikan program pengobatan, menggunakan medikasi secara tepat, dan mengikuti anjuran. Perilaku kepatuhan tergantung pada situasi klinis tertentu, sifat penyakit dan program pengobatan (Kaplan, 2010).

Pengobatan untuk mengatasi gejala-gejala skizofrenia membutuhkan waktu yang lama. Pada umumnya perilaku pasien skizofrenia sulit untuk diarahkan. Mereka cenderung mudah bosan dan malas melakukan seuatu. Lamanya penyakit tampaknya memberikan efek negatif terhadap kepatuhan pasien untuk minum obat. Semakin lama pasien menderita skizofrenia, maka semakin kecil pasien tersebut patuh pada pengobatannya. Obat berfungsi sebagai pengurang atau penghambat gejala positif 
(halusinasi, waham/delusi) atau negatif (penumpulan atau ketidaksesuaian emosi) pada pasien yang mengalami skizofrenia (Emila, 2017).

\section{KESIMPULAN}

Dari hasil penelitian dengan jumlah sampel sebanyak 50 pasien, dapat disimpulkan bahwa :

1. Kepatuhan minum obat pasien skizofrenia rendah sebesar $22 \%$, sedang $58 \%$, dan tinggi $20 \%$.

2. Tingkat kekambuhan pasien skizofrenia rendah sebesar $18 \%$, sedang $50 \%$, dan tinggi $32 \%$.

3. Analisis bivariat menggunakan uji chi square hasil menunjukkan $\rho$-value $=0,01$ lebih kecil dari nilai $\alpha=0,05$ yang menunjukkan bahwa terdapat hubungan kepatuhan minum obat dengan tingkat kekambuhan pasien skizofrenia di Poli Jiwa RSUD dr. H. Moch. Ansari Saleh Banjarmasin.

\section{DAFTAR PUSTAKA}

Agung, W., \& Arulita, I. F. (2016). Faktor Resiko Terjadinya Skizofrenia. Public Health Perspektive Journal 1(1).

Andri. (2008) Kongres Nasional Skizofrenia V Closing The Treathment Gap for Schizophernia. Badan Pengawas Obat dan Makanan.

Depkes RI. (2016). Peran Keluarga Dukung Kesehatan Jiwa Masyarakat. (diakses pada 9 Oktober 2017 melalui http://www.depkes.go.id/article/print/1610070 keluarga-dukungkesehatan-jiwa-masyarakat.html).

Depkes RI. (2013). Riset Kesehatan Dasar. Jakarta: Badan Penelitian dan pengembangan Kesehatan Kementrian Kesehatan RI.

Emila, P. (2017). Faktor yang Mempengaruhi Orang Dengang Gangguan Jiwa. Jurnal Perawat Indonesia 1(2). 58-62.

Fahrul, Alwiyah, M., \& Ingrid, F. (2014). Rasionalitas Penggunaan Antipsikotik pada Pasien Skizofrenia di Instalasi Rawat Inap Jiwa RSD Madani Sulawesi Tengah. Online Jurnal of Natural Science, 3(2):18-29.

Hawari, D. (2011). Manajemen Stress Cemas dan Ddepresi. Jakarta: Balai Penerbit FKUI.

Kaunang, I., Kaine, E., \& Kallo, V. (2015). Hubungan Kepatuhan Minum Obat Dengan Prevalensi Kekambuhan Pada Pasien Skizofrenia. Ejournal keperawatan. 2(2).

Kaplan, H. I., Sadock, B. J., \& Grebb, J. A., (2010). Sinopsisi Psikiatri Jilid 2. Terjemahan Widjaja Kusuma. Jakarta: Binarupa Aksara. P. 86-108.

Keliat, \& Budu, A. (2011). Keperawatan Kesehatan Jiwa Komunitas. Jakarta EGC.

Naafi, A. M., Perwitasari, D. A., \& Darmawan, E. (2016). Kepatuhan Minum Obat Pasien Rawat Jalan Skizofrenia di Rumah Sakit Jiwa Prof. dr. Soerojo Magelang. Kartika Jurnal IImiah Farmasi. 4(2), 7-12.

Yosep, I. (2011). Keperawatan Jiwa (Edisi Revisi). Refilan Aditama : Bandung

Yuliantika. Jumaini, Febriana, \& Sabrian. (2012). Faktor Faktor Yang Mempengaruhi Kepatuhan Minum Obat Pada Pasien Skizofrenia. Tersedia di http://repository.unri.ac.id >handle>JURNAl.pdf. 